University of Nebraska - Lincoln

DigitalCommons@University of Nebraska - Lincoln

Faculty Publications, Department of Mathematics

Mathematics, Department of

3-1932

\title{
THE PRACTICAL EVALUATION OF RESULTANTS
}

T. A. Pierce

University of Nebraska - Lincoln

Follow this and additional works at: https://digitalcommons.unl.edu/mathfacpub

Part of the Mathematics Commons

Pierce, T. A., "THE PRACTICAL EVALUATION OF RESULTANTS" (1932). Faculty Publications, Department of Mathematics. 44.

https://digitalcommons.unl.edu/mathfacpub/44

This Article is brought to you for free and open access by the Mathematics, Department of at DigitalCommons@University of Nebraska - Lincoln. It has been accepted for inclusion in Faculty Publications, Department of Mathematics by an authorized administrator of DigitalCommons@University of Nebraska - Lincoln. 


\section{THE PRACTICAL EVALUATION OF RESULTANTS}

By T. A. PIERCE, The University of Nebraska

The purpose of the present note is to give a practical method of evaluating the resultant of two equations. The method is particularly effective when the degree of one of the equations is high while that of the other is low.

Use will be made of certain results in the theory of matrices. Let $A$ be a square matrix and let $|A-\lambda I|=f(\lambda)=0$ be the characteristic equation of $A$. Then if $g(\lambda)=0$ be another equation, the resultant $R(f, g)$ of $f(\lambda)=0$ and $g(\lambda)=0$ is known (Frobenius, Journal für Mathematik, Vol. 84, p. 11) to be

$$
R(f, g)=|g(A)| \text {. }
$$

Furthermore if $B$ is the matrix which has $g(\lambda)=0$ as its characteristic equation then

$$
R(g, f)=|f(B)| \text {. }
$$

The matrix $A$ which has the given equation

$$
f(\lambda)=\lambda^{n}+a_{1} \lambda^{n-1}+a_{2} \lambda^{n-2}+\cdots+a_{n}=0
$$

as its characteristic equation is

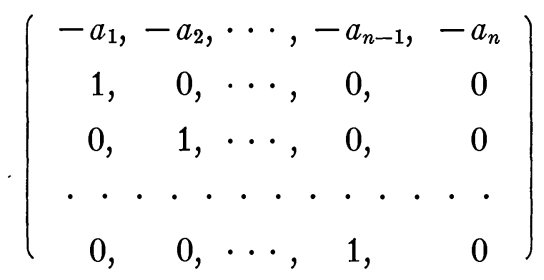

This is readily proved by forming the determinant of this matrix after having subtracted $\lambda$ from each element of the principal diagonal and expanding this determinant and each resulting determinant according to the elements of their last columns. Similarly the matrix $B$ which has

$$
g(\lambda)=\lambda^{m}+b_{1} \lambda^{m-1}+\cdots+b_{m}=0
$$

as its characteristic equation may be written down.

Since the left members of (1) and (2) differ at most by sign in obtaining the resultant of $f$ and $g$ it is only necessary to calculate that right member of (1) or (2) which is the simpler. It is this consideration of (2) in conjunction with (1) that makes our method practical. The matrices $A$ and $B$ are of order $n$ and $m$ respectively and $g(A)$ and $f(B)$ are matrices of orders $n$ and $m$. If $m<n$ we compute $|f(B)|$. In forming

$$
f(B)=B^{n}+a_{1} B^{n-1}+\cdots+a_{n-1} B+a_{n} I
$$

where $I$ is the unit matrix of order $m$ we first reduce this expression by means of

$$
g(B)=B^{m}+b_{1} B^{m-1}+\cdots+b_{m-1} B+b_{m} I=0,
$$

since $B$ satisfies its characteristic equation. Every power of $B$ higher than the 
$(m-1)$ st in $f(B)$ may be eliminated by using (5). In order to calculate these powers of $B$ some recursion formulas are needed. Let

$$
B^{r}=\alpha_{r} B^{m-1}+\beta_{r} B^{m-2}+\cdots+\lambda_{r} I
$$

where $r \geqq m$, then

$$
\begin{aligned}
B^{r+1} & =\alpha_{r} B^{m}+\beta_{r} B^{m-1}+\cdots+\lambda_{r} B \\
& =\left(\beta_{r}-b_{1} \alpha_{r}\right) B^{m-1}+\left(\gamma_{r}-b_{2} \alpha_{r}\right) B^{m-2}+\cdots+\left(-b_{m} \alpha_{r}\right) I b y(5) \\
& =\alpha_{r+1} B^{m-1}+\beta_{r+1} B^{m-2}+\cdots+\lambda_{r+1} I
\end{aligned}
$$

hence $\alpha_{r+1}=\beta_{r}-b_{1} \alpha_{r}, \beta_{r+1}=\gamma_{r}-b_{2} \alpha_{r}, \cdots, \lambda_{r+1}=-b_{m} \alpha_{r}$. These are the recursion formulas desired. It is now a simple process to calculate $f(B)$ and evaluate the determinant of the resulting matrix.

As an example we will find the resultant of

$$
\begin{aligned}
& f(\lambda)=\lambda^{12}+\lambda^{7}-\lambda^{4}-2 \lambda^{3}+3 \lambda+10=0 \\
& g(\lambda)=\lambda^{4}-\lambda^{2}+2 \lambda-3=0 .
\end{aligned}
$$

The dialytic method of Sylvester would give a determinant of order 16 . We have

$$
B=\left(\begin{array}{cccc}
0, & 1, & -2, & 3 \\
1, & 0, & 0, & 0 \\
0, & 1, & 0, & 0 \\
0, & 0, & 1, & 0
\end{array}\right)
$$

and must first find $f(B)$. To calculate $B^{12}$ and $B^{7}$ in terms of $B^{3}, B^{2}, B$, and $I$ we use the recursion formulas

$$
\alpha_{r+1}=\beta_{r}, \beta_{r+1}=\gamma_{r}+\alpha_{r}, \gamma_{r+1}=\delta_{r}-2 \alpha_{r}, \delta_{r+1}=3 \alpha_{r}
$$

with the initial values $\left(\alpha_{4}, \beta_{4}, \gamma_{4}, \delta_{4}\right) \equiv(0,1,-2,3)$. Hence

\begin{tabular}{l|rrrrrrrrr}
$r$ & 4 & 5 & 6 & 7 & 8 & 9 & 10 & 11 & 12 \\
\hline$\alpha_{r}$ & 0 & 1 & -2 & 4 & -4 & 11 & -18 & 31 & -52 \\
$\beta_{r}$ & 1 & -2 & 4 & -4 & 11 & -18 & 31 & -52 & 100 \\
$\gamma_{r}$ & -2 & 3 & -2 & 7 & -14 & 20 & -34 & 69 & -116 \\
$\delta_{r}$ & 3 & 0 & 3 & -6 & 12 & -12 & 33 & -54 & 93.
\end{tabular}

Thus $B^{12}=-52 B^{3}+100 B^{2}-116 B+93 I$ and $B^{7}=4 B^{3}-4 B^{2}+7 B-6 I$. Substituting these expressions in $f(B)$ we find $f(B)=-50 B^{3}+95 B^{2}-104 B+94 I$ and this is the matrix

$$
\left(\begin{array}{rrrr}
289, & -494, & 593, & -462 \\
-154, & 289, & -340, & 285 \\
95, & -154, & 194, & -150 \\
-50, & 95, & -104, & 94
\end{array}\right) .
$$

The value of the desired resultant is the determinant of this matrix and is 584549. 